Pak. j. sci. ind. res. Ser. B: biol. sci. 201356 (2) 90-97

\title{
Simultaneous Spectrophotometric Determination of Lycopene and Beta-Carotene Concentrations in Carotenoid Mixtures of the Extracts from Tomatoes, Papaya and Orange Juice
}

\author{
Misbaudeen Abdul-Hammed*, Isah Adewale Bello and Sunday Olusegun Oladoye \\ Department of Pure and Applied Chemistry, Ladoke Akintola University of Technology, \\ Ogbomoso, Nigeria
}

(received February 2, 2012; revised June 26, 2012; accepted June 27, 2012)

\begin{abstract}
A simple and inexpensive spectrophotometric equation model for the simultaneous determination of lycopene and $\beta$-carotene concentrations in a mixture of carotenoids is proposed. Lycopene could be exclusively determined (with the relative accuracy of more than 95\%) using the absorbance data at 502 $\mathrm{nm}$. Because quantifying the $\beta$-carotene concentration in a ccarotenoid minture using the sole absorbance at $450 \mathrm{~nm}$ is prone to error, an equation to determine the concentration of this compound from the absorbances data at two wavelengths was modeled. Using the modeled equations to re-check the molar absorptivity of lycopene at $472 \mathrm{~nm}$, the value obtained was about $98 \%$ close to the value reported in literature. The relative accuracy of the predicted concentrations of two carotenoids using the modeled equations is a function of the ratio of these carotenoids in the samples.
\end{abstract}

Keywords: lycopene, $\beta$-carotene, spectrophotometry, absorptivities, tomato, papaya, orange, isoprene

\section{Introduction}

Carotenoids, the $\mathrm{C}_{40}$ tetraterpenoids derived from headto-tail condensation of eight isoprenoid units, are notable for their wide distribution, structural diversity, and various functions. More than 600 carotenoids, excluding cis and trans isomers, have been isolated and characterized from natural sources (Pfander, 1987). Carotenoids have been credited with several beneficial effects on human health ranging from provitamin A activity to the enhancement of the immune response and reduction of the risk of degenerative diseases such as cancer, cardiovascular diseases, cataract, and macular degeneration (Olson 1999a; Astrog, 1997; Burri 1997; Mayne, 1996; Olson and Krinsky, 1995; Bendich, 1994; Krinsky, 1994; Gaziano and Hennekens, 1993). The action of carotenoids against chronic diseases has been mainly attributed to an antioxidant property, specifically, their ability to quench singlet oxygen and interact with free radicals (Palozza and Krinsky, 1992). However, other mechanisms, such as modulation of carcinogen metabolism, inhibition of cell proliferation, enhancement of cell differentiation and stimulation of cell-to-cell communication have been reported (Olson, 1999a; 1999b). The ability of carotenoids to quench singlet oxygen has been linked to the conjugated

*Author for correspondence; E-mail: misbaulhameed@yahoo.co.uk double bond system, the maximum efficiency being shown by carotenoids with nine or more conjugated double bonds (Foote et al., 1970). Lycopene was found to be twice more efficient than the dicyclic $\beta$-carotene (Di Mascio et al., 1989), despite of both compounds possessing 11 conjugated double bonds. The effects of lycopene on human health as an antioxidant protector against lung, stomach, and prostate cancers have attracted considerable interest (Giovannucci, 1999; Clinton, 1998; Sies and Stahl, 1998; Gerster, 1997; Stahl and Sies, 1996). Average daily dietary lycopene intake levels (assessed by means of food frequency questionnaire) were estimated to be 25.2 and 33.39 $\mathrm{mg} /$ day in the Canadian and Nigerian diets, respectively (Olajire et al., 2007; Rao et al., 1998).

Carotenoid analysis is inherently difficult and error prone. In developed countries, separation and quantification of carotenoids are usually carried out using high-performance liquid chromatography (HPLC) technique (Monge-Rojas and Campos, 2011; Barba et al., 2006). This method, although is reliable, accurate and time-consuming it requires extensive sample preparation, the use and disposal of hazardous organic solvents. It also requires highly trained personnel and expensive equipments. Novel chemical techniques that have been evaluated for direct determination of lycopene 
and other nutritionally important carotenoids include the application of optothermal and photothermal methods (Bicanic, 2011; Bicanic et al., 2005; 2004). These methods are gaining the popularity because of their simplicity. Other commonly used methods include resonance Raman spectroscopy (Bhosale et al., 2004), infrared (De Nardo et al., 2009; Halim et al., 2006) and near infrared spectroscopy (Baranska et al., 2006; Pedro and Ferreiram, 2005). Fourier transform infrared (FTIR) in combination with multivariate analysis offers a powerful and rapid technique for the analysis of agricultural and food products (Jha and Matsuoka, 2000). Conventional UV-visible spectrophotometric assays have also been shown to be simple, rapid, and inexpensive methods for measuring lycopene content in tomato and tomato products (Biswas et al., 2011; Davis et al., 2003), but absorbance interference from lycopene provides poor accuracy and overestimation of $\beta$-carotene levels (Olives-Barba et al., 2006). However, in some developing nations with limited accessibility to HPLC, the quantification of lycopene and $\beta$-carotene is often accomplished by means of the traditional ultraviolet-visible spectrophotometry. This method should be accurate enough, in that it has been shown that the content of lycopene in samples determined by the use of both experimental (calibration curve) and theoretical data (Beer-Lamberts law) shows a good agreement, with a relative error below 3\% (Ravelo-Pérez et al., 2008). Some published absorption coefficients values may contain significant levels of error or uncertainty (Britton, 1995), likewise different authors choose different absorption coefficients for same carotenoids (in the same solvents), thus accounting for a good part of the variations in analytical results. In some studies the spectrophotometer detector was set at $472 \mathrm{~nm}$ to quantify lycopene (Moraru and Lee, 2005; Sharma and Le Maguer, 1996) and at $436 \mathrm{~nm}$ (Lumpkin, 2005) while in others it was determined at $503 \mathrm{~nm}$ (Ravelo-Perez et al., 2008). Although the absorbance of lycopene at $503 \mathrm{~nm}$ is not the highest, it was so selected to avoid interferences from other carotenoids present in the samples. The values of $\lambda_{\max }$ for carotenoids in hexane and petroleum ether are practically the same for diethyl ether, methanol, ethanol and acetonitrile, and 2-6 nm, 10-20 nm, 10-20 nm and 18-24 nm higher in acetone, chloroform, and $n$ dichloromethane as well as in toluene, respectively (Britton, 1995). However, in a carotenoid mixture containing lycopene and $\beta$-carotene, the choice of absorption wavelengths of $450 \mathrm{~nm}$ and $470 \mathrm{~nm}$ to quantify $\beta$-carotene and lycopene, respectively may not reflect the true concentrations of each of the two carotenoids, since both absorb significantly at those two wavelength ranges, while the choice of $502 \mathrm{~nm}$ is perfect for lycopene determination. In the present work, the model equations for simultaneous determination of beta-carotene and lycopene concentrations in hexane layer extract of lycopene/ $\beta$-carotene mixtures have been derived. This was then used to quantify $\beta$-carotene and lycopene in separate hexane extracts of the carotenoid mixtures from tomatoes, papaya and orange juice samples.

\section{Materials and Methods}

Tomato fruit samples (Ibadan-local cultivar bought from a farmland near Wazobia Market, Ogbomoso, Nigeria) were randomly selected and packed into nylon bags and quickly taken into the laboratory, then they were rinsed with distilled water and left to drain for some minutes. About $500 \mathrm{~g}$ (15-25 fruits) of fresh tomatoes was chopped, blended and then homogenized in a laboratory homogenizer. Conventional solvent extraction methods (Perkins-Veazie et al., 2001; Sadler et al., 1990) were employed for carotenoid extraction. Approximately $10 \mathrm{~g}$ of the tomato serum was subjected to extraction with hexane, methanol and acetone $(2: 1: 1)$ containing $2.5 \%$ butylated hydroxytoluene (BHT). The extract was treated with distilled water, methanol and $20 \% \mathrm{KOH} /$ methanol $(1: 1: 1)$ to saponify any triglyceride present. The extract was then washed with distilled water and re-dissolved in hexane. The hexane extracts were scanned in the visible light wavelength range of 400-750 nm using HE $\lambda$ I0S $\alpha$ UV-visible spectrophotometer (in a $1 \mathrm{~cm}$ path length quartz cuvette blanked with $n$-hexane) and the maximum absorbances were observed at 450, 472 and $502 \mathrm{~nm}$, respectively for the lycopene - $\beta$-carotene hexane layer mixture. The mixture was diluted with $n$-hexane using dilution factors of 2, 3, 6, 8 and 16 , respectively to check for result consistencies and subsequent absorbances were measured. Samples of papaya and orange juice extracted in hexane were also subjected to carotenoid analysis. The molar extinction coefficient of 172,000 $\mathrm{L} / \mathrm{mol} / \mathrm{cm}$ at $502 \mathrm{~nm}$ was used to estimate lycopene concentration, using the Beer-Lamberts law (RaveloPerez et al., 2008; Zechmeister and Polgar, 1943).

\section{Results and Discussion}

Figure 1A-B represent typical overlap spectra of the hexane extract of the lycopene/ $\beta$-carotenoid mixture in tomatoes with absorption maxima at $450 \mathrm{~nm}, 472 \mathrm{~nm}$ 
and $502 \mathrm{~nm}$. Most carotenoids exhibit absorbance maxima at three wavelengths, resulting in a three-peak spectrum. As the number of conjugated double bonds increases, the $\lambda_{\max }$ shifts to longer wavelengths. Thus, the most unsaturated acyclic carotenoid, lycopene, with 11 conjugated double bonds is red and absorbs at the longest wavelengths ( $\lambda_{\max }$ at $443,471,502 \mathrm{~nm}$ ) (Rodriguez-Amaya and Kimura, 2004). Cyclization results in steric hindrance between the methyl group at C-5 of the ring and the hydrogen atom at C- 8 of the polyene chain. This hindrance takes the $\pi$ electrons of the ring double bond out of plane with respect to those of the chain, causing a hypsochromic shift (displacement of $\lambda_{\max }$ to shorter wavelength), a hypochromic effect (decrease in absorbance) and loss of fine structure (spectrum with less defined peaks). Thus, the dicyclic molecule, $\beta$-carotene, is yellow-orange and despite possessing the same number of conjugated double bonds as lycopene, exhibits absorption peaks at 450 and 472
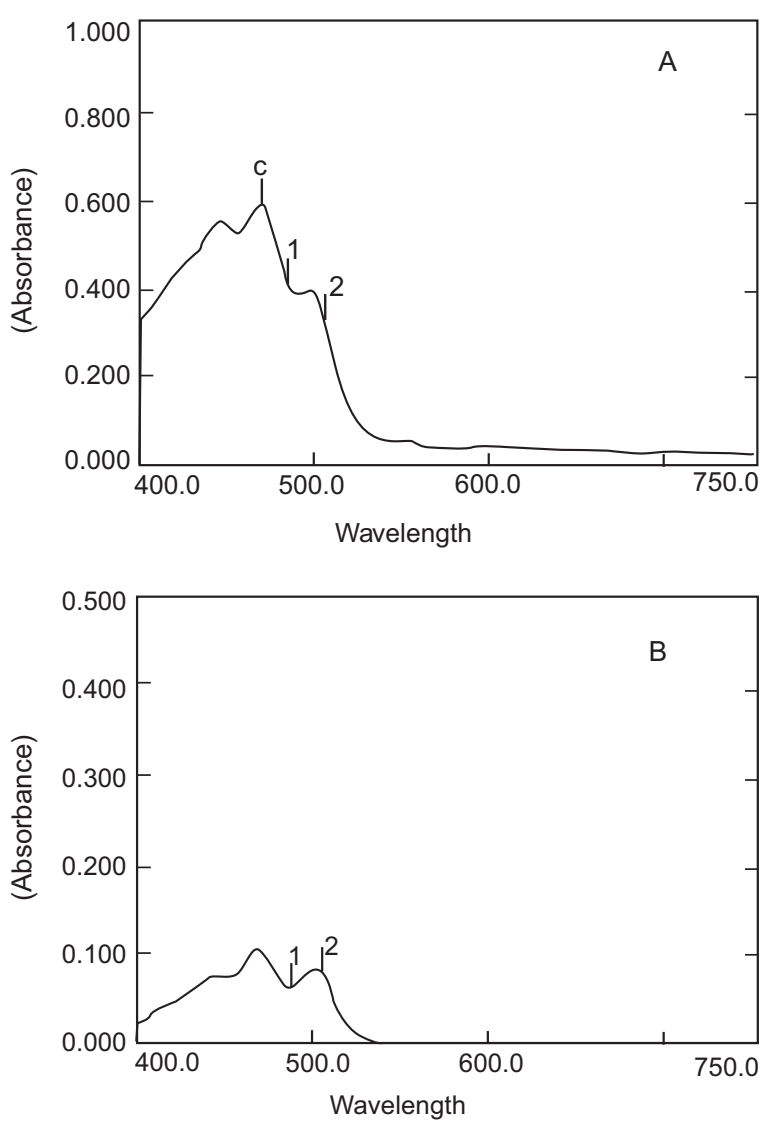

Fig. 1A-B.UV-visible spectra of $n$-hexane extract of the lycopene/ $\beta$-carotene mixture of tomato samples at dilution factors of (A) 1 (B) 16 . $\mathrm{nm}$ and a mere shoulder at $425 \mathrm{~nm}$ (Rodriguez-Amaya and Kimura, 2004). This is so because both carotenoids absorb substantially in the overlapping wavelength ranges. As already stated that the choice of $502 \mathrm{~nm}$ to quantify lycopene is alright despite the fact that this wavelength value is not equal to $\lambda_{\max }$ (Ravelo-Perez et al., 2008). The correlations of the absorbances of the mixture at $450 \mathrm{~nm}$ and $502 \mathrm{~nm}$ relative to those at 472 $\mathrm{nm}$, respectively (Fig. 2A-B) is very high $\left(\mathrm{R}^{2}=0.999\right.$ in both cases). This makes quantification of these carotenoids in mixture more ambiguous. Concentrations of lycopene and $\beta$-carotene in the mixture were calculated (Table 1) based on the assumption that the absorbances at $450 \mathrm{~nm}$ and at $502 \mathrm{~nm}$ are exclusively, for $\beta$-carotene and lycopene respectively. This is to be re-calculated using the proposed model and will then be compared henceforth. However, analytes such as
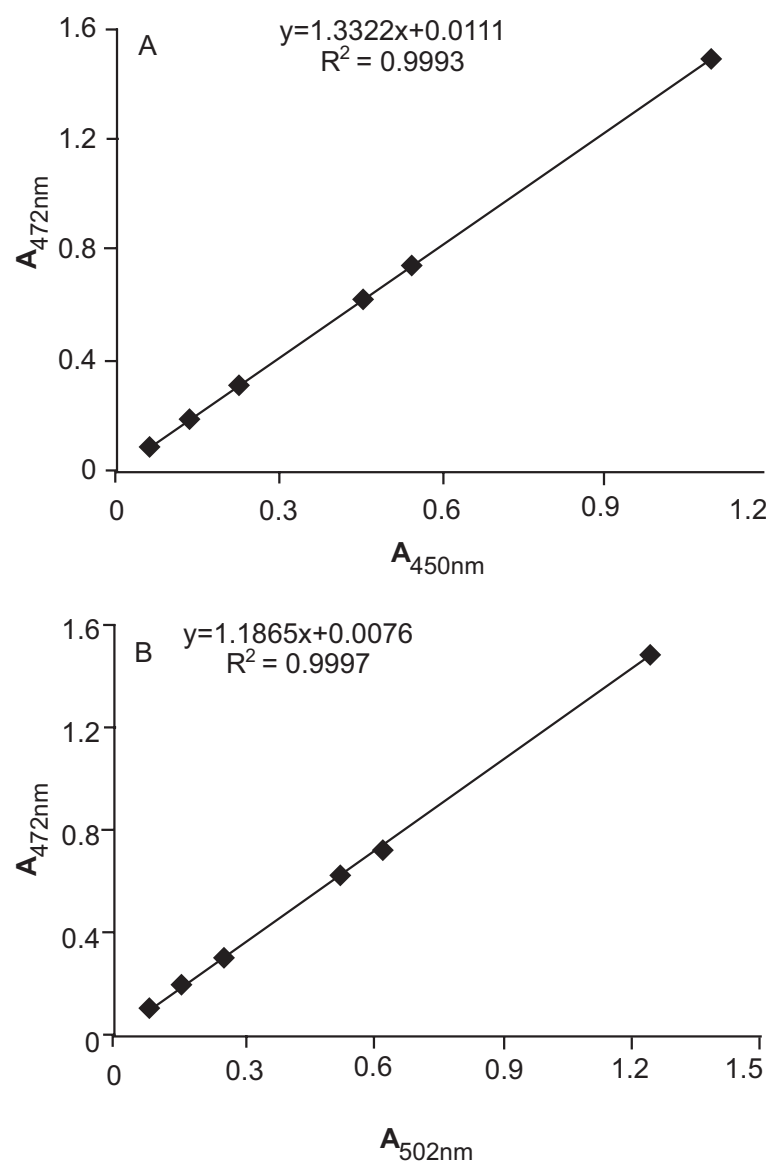

Fig. 2A-B. The correlations between the absorbances measured at $450 \mathrm{~nm}$ (A) and 502 (B) $\mathrm{nm}$ to that measured at $472 \mathrm{~nm}$ for the hexane extract of the lycopene/ $\beta$-carotene mixture of tomato samples. 
Table 1. The ideal molar concentrations of lycopene and $\beta$-carotene in tomatoes, (Ibadan- local cultivars) in case that absorbances at $450 \mathrm{~nm}$ and $502 \mathrm{~nm}$ are exclusively due to $\beta$-carotene and lycopene, respectively

\begin{tabular}{|c|c|c|c|c|c|}
\hline \multirow[t]{2}{*}{$\begin{array}{l}\text { Dilution } \\
\text { factors }\end{array}$} & \multicolumn{3}{|c|}{ Absorbances (nm) } & \multirow{2}{*}{$\begin{array}{l}{ }^{\mathrm{a}} \beta \text {-Carotene } \\
\text { concentration } \pm \mathrm{SD} \\
(\mu \mathrm{M})\end{array}$} & \multirow{2}{*}{$\begin{array}{l}{ }^{\mathrm{b}} \text { Lycopene } \\
\text { concentration } \pm \mathrm{SD} \\
(\mu \mathrm{M})\end{array}$} \\
\hline & $450 \mathrm{~nm}$ & 472 & 502 & & \\
\hline 1 & 1.100 & 1.487 & 1.240 & $7.929 \pm 0.202$ & $7.209 \pm 0.175$ \\
\hline 2 & 0.550 & 0.720 & 0.615 & $3.965 \pm 0.156$ & $3.576 \pm 0.129$ \\
\hline 3 & 0.453 & 0.620 & 0.516 & $3.265 \pm 0.162$ & $3.000 \pm 0.173$ \\
\hline 6 & 0.225 & 0.305 & 0.250 & $1.622 \pm 0.224$ & $1.453 \pm 0.032$ \\
\hline 8 & 0.133 & 0.191 & 0.152 & $0.959 \pm 0.102$ & $0.884 \pm 0.205$ \\
\hline 16 & 0.068 & 0.109 & 0.080 & $0.490 \pm 0.126$ & $0.465 \pm 0.092$ \\
\hline
\end{tabular}

${ }^{a}=$ Calculated from Beer-Lamberts Law using the absorbances at $450 \mathrm{~nm}$ and molar absorptivity of $1.39 \times 10^{5} \mathrm{~L} \mathrm{~mol} / \mathrm{cm} /(\mathrm{Du}$ et al., 1998); ${ }^{\mathrm{b}}=$ Calculated from Beer-Lamberts Law using the absorbances at $502 \mathrm{~nm}$ and molar absorptivity of $1.72 \times 10^{5}$ $\mathrm{L} \mathrm{mol} / \mathrm{cm}$ (Markovic et al., 2006); The results are the means of triplicate analysis with reported standard deviation (SD).

norfloxacin, ofloxacin and lomerfloxacin in their mixture have been determined simultaneously using chemometric method (Huang et al., 2009) and other analytes such as chlorpromazine, perphenazine and acetopromazine were quantified by kinetic wavelength-pair method (Carreto et al., 1997). Here, lycopene and $\beta$-carotene concentrations are determined by partial least squares calibration (Skoog et al., 2000). This involves determination of the absorbances of several solutions at the wavelength at which analytes, lycopene and $\beta$-carotene, absorb. The wavelengths were carefully chosen such that the molar absorptivity of one component is much larger than that of the second component. Therefore, absorbances at $450 \mathrm{~nm}$ and $502 \mathrm{~nm}$ were used where the molar absorptivities of $\beta$-carotene are $1.39 \times 10^{5}$ and $2.63 \times$ $10^{4} \mathrm{~L} / \mathrm{mol} / \mathrm{cm}$, respectively and those of lycopene being $1.16 \times 10^{5}$ and $1.72 \times 10^{5} \mathrm{~L} / \mathrm{mol} / \mathrm{cm}$, respectively. According to the law of Lamberts and Beer, the absorbance at $450 \mathrm{~nm}$ and $502 \mathrm{~nm}$ (in a $1 \mathrm{~cm}$ pathlength quartz cuvette) of the carotenoid mixture of lycopene and $\beta$-carotene can be expre as follows:

$A_{450}=\varepsilon_{\text {lycopene }}^{450}[$ Lycopene $]+\underset{\beta-\text { carotene }}{\varepsilon^{450}}[\beta-$ carotene $] \ldots$.

$A_{502}=\varepsilon_{\text {lycopene }}^{502}[$ Lycopene $]+\underset{\beta-\text { carotene }}{\varepsilon^{502}}[\beta-$ carotene $] \ldots . . .$.

where, $\mathrm{A}_{450}$ and $\mathrm{A}_{502}$ are the absorbances (at $1 \mathrm{~cm}$ cell path-length) of the lycopene/ $\beta$-carotene mixture in the hexane extract at $450 \mathrm{~nm}$ and $502 \mathrm{~nm}$, respectively; [lycopene] and [ $\beta$-carotene] are molar concentrations of lycopene and $\beta$-carotene, resspectively; $; \beta$-carotene and $\varepsilon_{\text {lycopene }}^{450}$ are the molar absorptivities of lycopene and $\beta$-carotene at $450 \mathrm{~nm}$ while $\varepsilon_{\beta \text {-carotene }}^{502}$ and $\varepsilon_{\text {lycopene }}^{502}$ represent the respective molar absorptivities of lycopene and $\beta$ carotene at $502 \mathrm{~nm}$.

Solving equations (1) and (2) simultaneously, the molar concentration of lycopene from equation (1) could be expressed as:

$[$ Lycopene $]=\left\{A_{450}-\varepsilon_{\beta-\text { carotene }}^{450}[\beta\right.$-carotene $\left.]\right\} / \int_{\text {lycopene }}^{450} \ldots \ldots$

Substituting equation (3) into equation (2), the concentration of $\beta$-carotene can be calculated as:

$$
\begin{aligned}
& A_{450} \frac{\varepsilon^{502}}{\varepsilon^{\text {lycopene }}}-A_{502}
\end{aligned}
$$

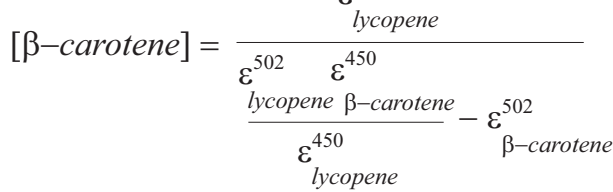

But the values $\varepsilon_{\beta \text {-carotene }}^{450}, \varepsilon_{\text {lycopene }}^{450}, \varepsilon_{\beta \text {-carotene }}^{502}$ and $\varepsilon_{\text {lycopene }}^{502}$ are known to be $1.39 \times 10^{5}, 1.16 \times 10^{5}, 2.63 \times 10^{4}$ and $1.72 \times 10^{5} \mathrm{~L} / \mathrm{mol} / \mathrm{cm}$, respectively (Clinton, 1998; Du et al., 1998; Krinsky et al., 1990; Zechmeister and Polgar, 1943), therefore:

$$
\begin{aligned}
& {[\beta \text {-carotene }]=\frac{1.483 A_{450}-A_{502}}{1.798 \times 10^{5}}} \\
& {[\text { Lycopene }]=\frac{A_{450}-1.39 \times 10^{5}[\beta \text {-carotene }]}{1.16 \times 10^{5}} \approx \frac{A_{502} \ldots \ldots \ldots \ldots . . .(5)}{1.72 \times 10^{5}}}
\end{aligned}
$$

Equations (5) and (6) were employed to calculate the concentrations of lycopene and $\beta$-carotene, respectively 
and the results are as presented in Table 2. It was clearly shown that the use of the absorbances at $450 \mathrm{~nm}$ to exclusively determine $\beta$-carotene concentration is extremely prone to error. This is so because the relative accuracy of the predicted $\beta$-carotene concentration using the modeled equations compared with what could have been reported when its concentration was calculated from their absorbance values at $450 \mathrm{~nm}$, is extremely low (an average of $26.78 \%$ ). However, it could be inferred that absorbance at $502 \mathrm{~nm}$ could be exclusively attributed to lycopene, since an average relative accuracy of more than $95 \%$ was obtained. This is in agreement with other study (Fish et al., 2002) which suggests that constituent carotenoids other than lycopene will contribute to the absorbance at $503 \mathrm{~nm}$ up to about 4\% for fresh red tomatoes, $2 \%$ for red-fleshed watermelon and $6 \%$ for pink grapefruit. This also corroborated the findings that the lycopene contents in different varieties of tomatoes, analyzed by UV-visible spectrophotometry at $502 \mathrm{~nm}$ and HPLC methods, are quite similar (Laleye et al., 2010).
To check for the correctness of the lycopene concentration at $472 \mathrm{~nm}$, equation 1 may be re-written as:

$A_{472}=\varepsilon_{\text {lycopene }}^{472}[$ Lycopene $]+\underset{\beta \text {-carotene }}{\varepsilon^{472}}[\beta$-carotene $] \ldots . . .(7)$

Assuming $\varepsilon_{\text {lycopene }}^{472}$ to be unknown, it can be calculated thus:

$\varepsilon_{\text {lycopene }}^{472}=\frac{A_{472}-\varepsilon^{472}[\beta \text {-carotene }}{[\text { Lycopene }]}$

Substituting the value of $\mathrm{A}_{472}$ and $\varepsilon_{\beta \text {-carotene }}^{472}=1.09 \times 10^{5}$ $\mathrm{L} / \mathrm{mol} / \mathrm{cm}$ (Du et al., 1998) as well as the concentrations of lycopene and $\beta$-carotene of the stock solution (solution of dilution factor of 1 , that is 6.876 and $2.175 \mu \mathrm{M}$

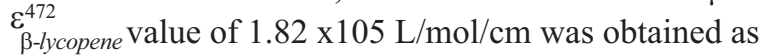
against a value of $1.86 \times 105 \mathrm{~L} / \mathrm{mol} / \mathrm{cm}$ previously reported by Clinton (1998). This gives a relative accuracy (ratio of predicted value to the true value) of about $98 \%$.

The absorption spectra of the hexane extracts samples of papaya and orange juice Fig. 3A-B are shown in Equations (5) and (6) were then tested on the absorbance

Table 2. Predicted concentrations of lycopene and $\beta$-carotene in the hexane extract from tomatoes (Ibadan-local cultivar)

\begin{tabular}{|c|c|c|c|c|c|c|c|}
\hline \multirow[b]{2}{*}{$\begin{array}{l}\text { Dilution } \\
\text { factors }\end{array}$} & \multicolumn{3}{|c|}{ Absorbances (nm) } & \multirow{2}{*}{$\begin{array}{l}{ }^{\mathrm{a}} \beta \text {-Carotene } \\
\text { concentration } \\
\pm \mathrm{SD}(\mu \mathrm{M})\end{array}$} & \multirow{2}{*}{$\begin{array}{l}{ }^{\mathrm{b}} \text { Lycopene } \\
\text { concentration } \\
\pm \mathrm{SD}(\mu \mathrm{M})\end{array}$} & \multicolumn{2}{|c|}{${ }^{\mathrm{c}}$ Relative accuracy } \\
\hline & $\overline{450}$ & 472 & 502 & & & $\begin{array}{l}\beta \text {-carotene } \\
\text { at } 450 \mathrm{~nm}\end{array}$ & $\begin{array}{l}\text { Lycopene } \\
\text { at } 502 \mathrm{~nm}\end{array}$ \\
\hline 1 & 1.100 & 1.487 & 1.240 & $2.175 \pm 0.127$ & $6.876 \pm 0.212$ & 27.431 & 95.377 \\
\hline 2 & 0.550 & 0.720 & 0.615 & $1.116 \pm 0.062$ & $3.404 \pm 0.156$ & 28.150 & 95.201 \\
\hline 3 & 0.453 & 0.620 & 0.516 & $0.870 \pm 0.152$ & $2.866 \pm 0.124$ & 26.644 & 95.533 \\
\hline 6 & 0.225 & 0.305 & 0.250 & $0.466 \pm 0.094$ & $1.381 \pm 0.136$ & 28.733 & 95.013 \\
\hline 8 & 0.133 & 0.191 & 0.152 & $0.250 \pm 0.022$ & $0.847 \pm 0.087$ & 26.057 & 95.845 \\
\hline 16 & 0.068 & 0.109 & 0.080 & $0.116 \pm 0.013$ & $0.448 \pm 0.056$ & 23.666 & 96.320 \\
\hline Average percentages & - & - & - & - & - & 26.780 & 95.548 \\
\hline
\end{tabular}

${ }^{a}=$ Calculated using equation (5); ${ }^{b}=$ Calculated using equation (6); The results are the means of triplicate analysis with reported standard deviation $(\mathrm{SD}) ;{ }^{\mathrm{c}}=$ Relative accuracy means the ratio of the predicted concentrations of lycopene and $\beta$ carotene when the modeled equations were used relative to what could have been reported when their concentrations were calculated from their absorbance values at $502 \mathrm{~nm}$ and $450 \mathrm{~nm}$, the wavelengths assumed to be attributed exclusively to the respective carotenoids in their mixtures.

Table 3. Predicted concentrations of lycopene and $\beta$-carotene in papaya and orange juice

\begin{tabular}{|c|c|c|c|c|c|c|}
\hline \multirow[t]{2}{*}{${ }^{\text {a Sample }}$} & \multicolumn{2}{|c|}{ Absorbances (nm) } & \multirow{2}{*}{$\begin{array}{l}{ }^{\mathrm{b}} \beta \text {-Carotene } \\
\text { concentration } \\
(\mu \mathrm{M})\end{array}$} & \multirow{2}{*}{$\begin{array}{l}{ }^{\mathrm{c}} \text { Lycopene } \\
\text { concentration } \\
(\mu \mathrm{M})\end{array}$} & \multirow{2}{*}{$\begin{array}{l}\beta \text {-Carotene } \\
\text { concentration } \\
(\mu \mathrm{g} / \mathrm{g})\end{array}$} & \multirow{2}{*}{$\begin{array}{l}\text { Lycopene } \\
\text { concentration } \\
(\mu \mathrm{g} / \mathrm{g})\end{array}$} \\
\hline & 450 & 502 & & & & \\
\hline Papaya & 0.585 & 0.401 & $2.590 \pm 0.132$ & $1.934 \pm 0.124$ & $27.765 \pm 1.415$ & $20.732 \pm 1.329$ \\
\hline Orange juice & 0.123 & 0.051 & $0.731 \pm 0.092$ & $0.185 \pm 0.022$ & $7.836 \pm 0.986$ & $1.983 \pm 0.236$ \\
\hline
\end{tabular}

${ }^{\mathrm{a}}=$ Sample weight is $10 \mathrm{~g}$ and the volume of hexane extract is $200 \mathrm{~mL} ;{ }^{\mathrm{b}}=$ calculated using equation $(5) ;{ }^{\mathrm{c}}=$ calculated using equation (6); The results are the means of triplicate analysis with reported standard deviation (SD). 

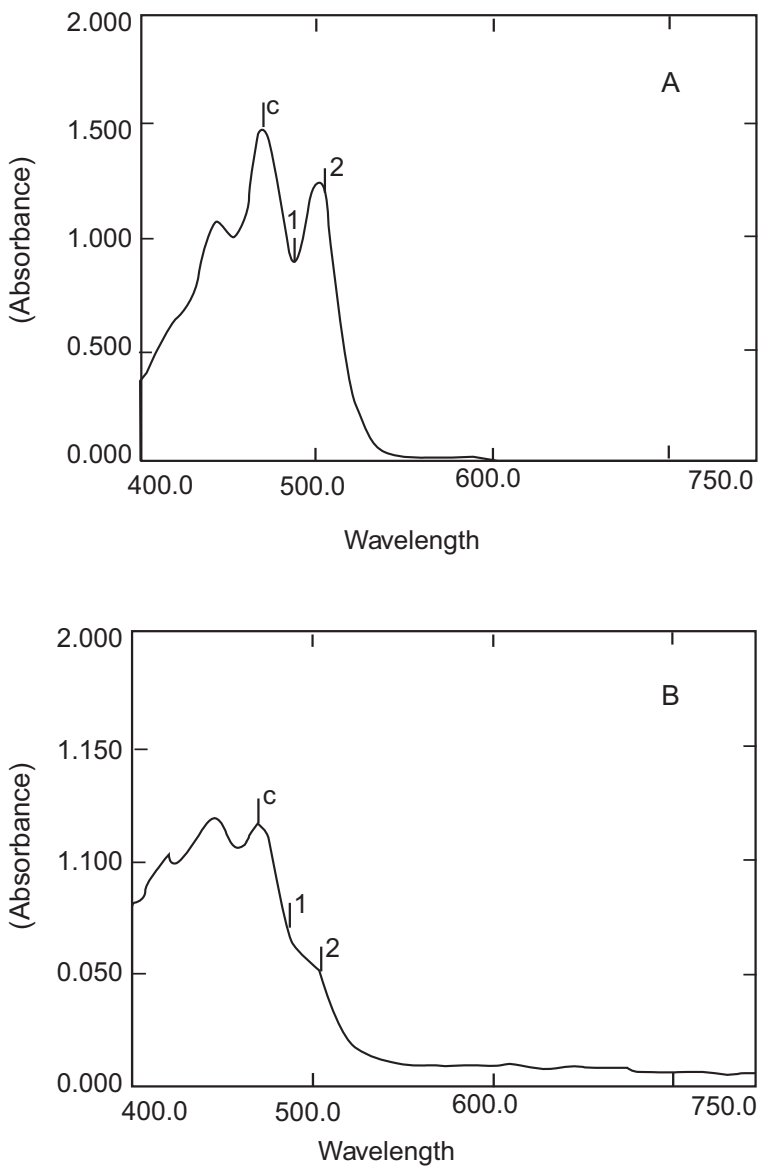

Fig. 3A-B. UV-visible spectra of $n$-hexane extract of the lycopene $/ \beta$-carotene mixture in samples of (A) orange juice (B) papaya.

results of the hexane extract of papaya and orange juice samples to calculate the respective amounts of $\beta$-carotene and lycopene in the lycopene/ $\beta$-carotene mixture. The results are presented in Table 3 . The results with other fruit or fruit product apart from tomatoes confirm that the $\beta$-carotene concentrations are higher than that of lycopene. This is evident from the spectra shown in Fig. 3A-B. High relative accuracy values of the predicted $\beta$-carotene concentration relative to that computed exclusively at $450 \mathrm{~nm}$ of $61.42 \%$ and $82.45 \%$ were observed for papaya and orange juice, respectively in contrast with an average of $26.78 \%$ observed for tomato fruits. Furthermore, the relative accuracies $(82.95 \%$ and $62.39 \%$ ) of the predicted lycopene relative to that computed exclusively at $502 \mathrm{~nm}$ observed for papaya and orange juice, respectively are lower than an average of $95.55 \%$ obtained for tomatoes. This may be attributed to lycopene/ $\beta$-carotene concentration ratio in the sample under investigation or/and the presence of appreciable amounts of other hydrocarbon carotenoids in papaya and orange. It is hereby recommended that the predicted equations in this work be employed in the determination of concentrations of lycopene and $\beta$-carotene in the hexane extract of lycopene/ $\beta$-carotene mixture and the results can be compared with those from HPLC analysis, to check for precision and accuracy.

\section{Conclusion}

A simple and inexpensive spectrophotometric equation model for the simultaneous determination of lycopene and $\beta$-carotene concentrations in a carotenoid mixture is proposed. This could be useful to analysis in some developing nations where UV-visible spectrophotometry is available but accessibility to HPLC is minimal. The equations proposed here worked best if the percentage composition of other hydrocarbon carotenoids (relative to lycopene and $\beta$-carotene) in the hexane extract is minimal.

\section{Acknowledgement}

The authors acknowledge the support of German Academic Exchange Service (DAAD), Germany for the grant for the purchase of small equipments and materials offered to the corresponding author. The research aid to young researchers by the Faculty of Pure and Applied Sciences, LAUTECH, Ogbomoso is also acknowledged.

\section{References}

Astrog, P. 1997. Food carotenoids and cancer prevention: An overview of current research. Trends in Food Science and Technology, 81: 406-413.

Baranska, M., Schutze, W., Schulz, H. 2006. Determination of lycopene and $\beta$-carotene content in tomato fruit and related products: Comparison of FT-Raman, ATR-IR, and NIR spectroscopy. Analytical Chemistry, 78: 8456-8461.

Barba, A.I.O., Hurtado, M.C., Mata, M.C.S., Ruiz, V.F., de Tejada, M.L.S. 2006. Application of a UV-Vis detection-HPLC method for a rapid determination of lycopene and $\beta$-carotene in vegetables. Food Chemistry, 95: 328-336.

Bendich, A. 1994. Recent advances in clinical research involving carotenoids. Pure and Applied Chemistry, 66: 1017-1024.

Bhosale, P., Ermakov, I.V., Ermakova, M.R., Gellermann, W., Bernstein, P.S. 2004. Resonance Raman quantification of nutritionally important carotenoids in fruits, vegetables, and their juices 
in comparison to high-pressure liquid chromatography analysis. Journal of Agricultural and Food Chemistry, 52: 3281-3285.

Bicanic, D.D. 2011. On the photoacoustic, photothermal and colorimetric quantification of carotenoids and other phytonutrients in some foods: a review. Journal of Molecular Structure, 993: 9-14.

Bicanic, D., Fogliano, V., Luterotti, S., Swarts, J., Piani, G., Graziani, G. 2005. Quantification of lycopene in tomato products: comparing the performances of newly proposed direct photothermal methods and high performance liquid chromatography. Journal of the Science of Food and Agriculture, 85: 1149-1153.

Bicanic, D., Swarts, J., Luterotti, S., Pietraperzia, G., Dóka, O., de Rooij, H. 2004. Quantification of lycopene in products derived from thermally processed tomatoes: Optothermal window as a selective, sensitive, and accurate analytical method without the need for preparatory steps. Analytical Chemistry, 76: 5203-5207.

Biswas, A.K., Sahoo, J., Chatli, M.K. 2011. A simple UV-Vis spectrophotometric method for determination of $\beta$-carotene content in raw carrot, sweet potato and supplemented chicken meat nuggets. Food Science and Technology, 44: 1809-1813.

Britton, G. 1995. UV/visible spectroscopy. In: Carotenoids: Spectroscopy, G., Britton, Liaaen- S., Jensen, and H. Pfander (eds), vol. 1B, pp. 13-63, Birkhäuser Verlag, AG, Basel, Switzerland.

Burri, B.J. 1997. Beta-carotene and human health: A review of current research. Nutrition Research, 17: 547-580.

Carreto, M.L., Lunar, L., Rubio, S., Perez-Bendito, D. 1997. Simultaneous spectrophotometric determination of chlorpromazine, perphenazine and acetopromazine by use of kinetic wavelength pair method. Analytica Chimica Acta, 349: 33-42.

Clinton, S.K. 1998. Lycopene: Chemistry, biology, and implications for human health and disease. Nutrition Reviews, 56: 35-51.

Davis, A.R., Fish, W.W., Perkins-Veazie, P. 2003. A rapid spectrophotometric method for analyzing lycopene content in tomato and tomato products. Postharvest Biological Technology, 28: 425-430.

De Nardo, T., Shiroma-Kian, C., Halim, Y., Francis, D., Rodriguez-Saona, L.E. 2009. Rapid and simultaneous determination of lycopene and $\beta$ carotene contents in tomato juice by infrared spectroscopy. Journal of Agricultural and Food
Chemistry, 57: 1105-1112.

Di Mascio, P., Kaiser, S., Sies, H. 1989. Lycopene as the most efficient biological carotenoid singlet oxygen quencher. Archives of Biochemistry and Biophysics, 274: 532-538.

Du, H., Fuh, R.A., Li, J., Corkan, A., Lindsey, J.S. 1998. PhotochemCAD: A computer-aided design and research tool in photochemistry. Photochemistry and Photobiology, 68: 141-142.

Fish, W.W., Perkins-Veazie, P., Collins, J.K.. 2002. A quantitative assay for lycopene that utilizes reduced volumes of organic solvents. Journal of Food Composition and Analysis, 15: 309-317.

Foote, C.S., Chang, Y.C., Denny, R.W. 1970. Chemistry of singlet oxygen: Carotenoid quenching parallels biological protection. Journal of the American Chemical Society, 92: 5216-5218.

Gaziano, J.M., Hennekens, C.H. 1993. The role of beta-carotene in the prevention of cardiovascular disease. Annals of the New York Academy of Science, 691: 148-155.

Gerster, H.Y. 1997. The potential role of lycopene for human health. Journal of the American College of Nutrition, 16: 109-126.

Giovannucci, E. 1999. Tomatoes, tomato-based products, lycopene, and cancer: Review of the epidemiologic literature. Journal of National Cancer Institute, 91: 317-331.

Halim, Y., Schwartz, S.J., Francis, D., Baldauf, N.A., Rodriguez-Saona, L.E. 2006. Direct determination of lycopene content in tomatoes (Lycopersion esculentum) by attenuated total reflectance infrared spectroscopy and multivariate analysis. Journal of Association of Official Analytical Chemist International, 89: 1257-1262.

Huang, X.G., Zhang, H.S., Li, Y.X., Li, M.F. 2009. Simultaneous spectrophotometric determination of Norfloxacin, Ofloxacin and Lomerfloxacin in rabbit blood serum by the use of chemometrics. Journal of Chilean Chemical Society, 54: 204-207.

Jha, S.N., Matsuoka, T. 2000. Nondestructive techniques for quality evaluation of intact fruits and vegetables. Food Science and Technology Research, 6: 248-251.

Krinsky, N.I. 1994. Actions of carotenoids in biological systems. Annual Reviews of Nutrition, 13: 561-587.

Krinsky, N.I., Russett, M.D. Handelman, G.J., Snodderly, D.M. 1990. Structural and geometrical isomers of carotenoids in human plasma. Journal of Nutrition, 120: $1654-1662$.

Laleye, L.C., Al Hammadi, S.I., Jobe, B., Rao, M.V. 
2010. Assessment of lycopene contents of fresh tomatoes (Lycopersicon esculentum Mill.) and tomato products in the United Arab Emirates. Journal of Food, Agriculture and Environment, 8: 142-147.

Lumpkin, H. 2005. A comparison of lycopene and other phytochemicals in tomatoes grown under conventional and organic management systems. Technical Bulletin No. 34, Asian Vegetable Research and Development Center (publication number 05-623), 48 pp., The World Vegetable Center, Shanhua, Taiwan.

Markovic, K., Hruskar, M., Vahcic, N. 2006. Lycopene content of tomato products and their contribution to the lycopene intake of croatian. Nutritional Research, 26: 556-560.

Mayne, S.T. 1996. Beta-carotene, carotenoids, and disease prevention in humans. Federation of American Societies for Experimental Biology Journal, 10: 690-701.

Monge-Rojas, R., Campos. H. 2011. Tocopherol and carotenoid content of foods commonly consumed in Costa Rica. Journal of Food Composition and Analysis, 24: 202-216.

Moraru, C., Lee, T. 2005. Kinetic studies of lycopene isomerization in a tributyrin model system at gastric pH. Journal of Agricultural and Food Chemistry, 53: 8997-9004.

Olajire, A.A., Ibrahim, A.O., Adelowo-Imeokparia F.E., Abdul-Hammed, M. 2007. Lycopene in tomato and tomato-based products: Levels and their contribution to dietary lycopene. Pakistan Journal of Scientific Industrial Research, 50: 18-21.

Olives Barba, A.I., Camara Hurtado, M., Sanchez Mata, M.C., Fernandez Ruiz, V., Lopez Saenz de Tejada, M. 2006. Application of a UV-vis detection-HPLC method for a rapid determination of lycopene and $\beta$-carotene in vegetables. Food Chemistry, 95: 328-336.

Olson, J.A. 1999a. Carotenoids. In: Modern Nutrition in Health and Disease,M.E., Shils, J.A., Olson, M., Shike and A.C. Ross, (eds), pp. 525-541, $9^{\text {th }}$ edition. Williams and Wilkins, Baltimore, USA.

Olson, J.A. 1999b. Carotenoids and human health. Archivos of Latinoamericanos de Nutrition, 49: 7S-11S.

Olson, J.A., Krinsky, N.I. 1995. Introduction: The colorful, fascinating world of the carotenoids: Important physiologic modulators. Journal of Federation of American Societies for Experimental Biology, 9: 1547-1550.
Palozza, P., Krinsky, N.I. 1992. Antioxidant effects of carotenoids in vivo and in vitro: An overview. Methods in Enzymology, 213: 403-420.

Pedro, A.M.K., Ferreira, M.M.C. 2005. Nondestructive determination of solids and carotenoids in tomato products by near-infrared spectroscopy and multivariate calibration. Analytical Chemistry, 77: 2505-2511.

Perkins-Veazie, P., Collins, J. K., Pair, S. D., Roberts, W. 2001. Lycopene content differs among redfleshed watermelon cultivars. Journal of the Science of Food and Agriculture, 81: 983-987.

Pfander, H. 1987. Key to carotenoids, 45 pp., 2nd edition, Birkhäuser Verlag, Basel, Switzerland.

Rao, A.V., Zeeshan, W., Sanjiv, A. 1998. Lycopene content of tomatoes and tomato products and their contribution to dietary lycopene. Food Research International, 31: 737-741.

Ravelo-Pérez, L.M., Hernández-Borges, J., RodríguezDelgado, M.A., Borges-Miquel, T. 2008. Spectrophotometric Analysis of Lycopene in Tomatoes and Watermelons: A Practical Class. Chemical Educator, 13: 11-13.

Rodriguez-Amaya, D.B., Kimura, M. 2004. HarvestPlus Handbook for Carotenoid Analysis, 63 pp., HarvestPlus Technical Monograph Series. 2, Washington, DC. USA.

Sadler, G., Davis, J., Dezman, D. 1990. Rapid extraction of lycopene and $\beta$-carotene from reconstituted tomato paste and pink grapefruit homogenates. Journal of Food Science, 55: 1460-1461.

Sharma, S.K., Le Maguer, M. 1996. Kinetics of lycopene degradation in tomato pulp solids under different processing and storage conditions. Food Research International, 29: 309-315.

Sies, H., Stahl, W. 1998. Lycopene: Antioxidant and biological effects and its bioavailability in the human. In: Proceedings of the Society of Experimental Biology and Medicine (New York, USA), 218: 121-124.

Skoog, D.A., West, D.M., Holler, F.J., Crouch, S.R. 2000. Analytical Chemistry: An Introduction, pp. $604-608,7^{\text {th }}$ edition. Saunder College Publication, USA.

Stahl, W., Sies, H. 1996. Lycopene: A biologically important carotenoid for humans? Archives of Biochemistry and Biophysics, 336: 1-9.

Zechmeister, L., Polgar, A. 1943. Cis-trans isomerization and spectral characteristics of carotenoids and some related compounds. Journal of the American Chemical Society, 65: 1522-1528. 